\title{
The Effect of Expressive Writing on Postpartum Depression and Stress of Mothers with a Preterm Infant in NICU
}

\author{
Soheila Rabiepoor ${ }^{1} \cdot$ Naemeh Vatankhah-Alamdary $^{2}$ (I) $\cdot$ Hamid Reza Khalkhali $^{3}$
}

Published online: 10 December 2019

(c) Springer Science+Business Media, LLC, part of Springer Nature 2019

\begin{abstract}
This study was conducted to investigate the effects of expressive writing on postpartum depression and stress of mothers with a preterm infant in NICU. This clinical trial was carried out on 91 mothers whose infants were in NICU. Subjects were assigned to intervention and control groups. In the intervention group, subjects were asked to start expressive writing from the third day of hospitalization in NICU and continue it until the tenth day. EPDS, PSS: NICU, and PSS-14 COHEN were completed by all the mothers on days 3 and 10, and 1-3 months after the admittance. Mean EPDS score was obtained as $9.65 \pm 5.28,9.23 \pm 5.41,8.19 \pm 4.45$, and $7.60 \pm 4.65$, respectively, for control group at days 3 and 10 , and $1-3$ months after hospitalization, and it was also obtained as $9.62 \pm 5.89,6.04 \pm 3.39,2.95 \pm 2.41$, and $2.44 \pm 2.01$, respectively, for the intervention group at days 3 and 10, and 1-3 months after hospitalization $(p<0.001)$. Mean PSS-14 COHEN score was lower for intervention group similar to the control group $(p<0.005)$. Results of the independent samples $T$-test showed higher stress scores for the control group before and after the intervention, but the difference was not statistically significant $(p=0.08)$. Mothers with an infant in NICU experienced a high level of postpartum depression and stress. Thus, according to findings of this study, expressive writing is proposed as a convenient and inexpensive means to reduce levels of postpartum depression and stress.
\end{abstract}

Keywords Postpartum depression $\cdot$ Preterm infant $\cdot$ Expressive writing $\cdot$ NICU $\cdot$ Perceived stress

\section{Introduction}

A population of 15 million babies in the world, accounting for more than one in ten births are born too early annually (Althabe, 2012). Similarly, in Iran, about 5.6-39.4\% of babies are delivered premature (Dolatian et al., 2013). A preterm infant is immediately separated from its mother and transferred to NICU to receive healthcare services by trained staff (Lasiuk, Comeau, \& Newburn-Cook, 2013). This is accompanied by psychological and emotional stress

Naemeh Vatankhah-Alamdary

vatankhah.na@gmail.com

1 Reproductive Health Research Center, Urmia University of Medical Sciences, Urmia, Iran

2 Midwifery Department, Urmia University of Medical Sciences, Campus Nazlu, 11KM Road Sero, Urmia, West Azarbaijan, Iran

3 Department of Biostatistics and Epidemiology, Inpatient's Safety Research Center, Urmia University of Medical Sciences, Urmia, Iran for both parents and the infant (Russell et al., 2014). Parents worry about their newborn baby handed over to the modern and highly technological world of NICU whose survival is at stake if anything goes wrong (Hawes, McGowan, O'donnell, Tucker, \& Vohr, 2016). Sense of psychological, physical, and emotional detachment from the baby, coupled with lack of information and continual fear of mishaps, makes an intensively stressful time for the parents (Kadivar, Seyedfatemi, Akbari, \& Haghani, 2015). Fear of losing the baby haunts the mothers whose infants are in NICU, and makes them more prone to psychological distress and acute stress (28-40\%) (Lefkowitz, Baxt, \& Evans, 2010; Misund, Nerdrum, \& Diseth, 2014).

Postpartum depression has been reported to have adverse effects on mother-child interactions, child cognitive development, and may lead to poor child outcomes (Murray, Halligan, $\&$ Cooper, 2010). This is further complicated by perceived parental stress related to feelings of helplessness, being isolated from the baby and not knowing how to interact with infants in the NICU (Chertok, McCrone, Parker, Leslie, \& Catlin, 2014). The change in parental role is the most prevalent 
cause of anxiety and depressive disorders occurring in the parents. However, there are other factors including doubts concerning infant survival, ability of the family to take care of the baby, sense of guilt, and physical as well as psychosocial concerns (Kadivar, Seyedfatemi, Akbari, Haghani, \& Fayaz, 2017). This stressful experience becomes even worse with physical atmosphere of NICU consisting of monitors, lights, equipment, heat, noise, frequent visit by the doctors and nurses, the crowd, tubes attached to the baby, and sense of parental exclusion from childcare (Chertok et al., 2014).

Non-pharmacological interventions such as Newborn Individualized Developmental Care and Intervention Program (NIDCAP), music therapy, Kangaroo Mother Care (KMC), and expressive writing (Hasanpour et al., 2018; Kadivar et al., 2017; Kolmakova, 2015; Mizutani, 2016; Morgan et al., 2018) have been administered in previous studies to alleviate stress and depressive disorders of mothers whose infants are in NICU. Expressive writing is a technique in which people usually write about an uncomfortable experience about 15-20 min a day for 3 or 4 days. Expressive writing is also defined as an intervention, whereby the individuals expresses their thoughts and feelings related to a traumatic event to regain their biological and physical well-being (Pennebaker, 2018).Studies conducted in the last two decades show that keeping a journal of expressive writing about a traumatic or stressful event has significant effects in promoting mental and physical health and reducing stress levels (Kadivar et al., 2015). It also enhances the relationship between mothers and nurses, improves awareness of neonatal caregiving, skill adaptation, problem-solving ability, and personal development. Expressive writing is most effective when an agonizing event is hard to be disclosed orally (Drake \& Winner, 2012; Rude \& Haner, 2018).

Studies showed that expressive writing influences stress and depression (Krpan et al., 2013; Milbury et al., 2017; Perry \& Ward-Smith, 2018; Reinhold, Bürkner, \& Holling, 2018). According to the DSM-5, postpartum psychosis is recognized as a subtype of major mood disorder. Antipsychotic medications are not prescribed to breastfeeding mothers because they may incur side effects (Sadock, Sadock, \& Ruiz, 2014). On the contrary, expressive writing is convenient, cost-effective, more acceptable, and is easily controlled by the patients (Krpan et al., 2013). It is assumed to effectively suppress postpartum depression and stress. Thus, the present study was conducted to investigate the effect of expressive writing on postpartum depression and stress of mothers whose infants are in NICU.

\section{Materials and Methods}

This experimental research with pre- and post-test designs was performed to investigate the effects of expressive writing on depression and stress of mothers who had a preterm infant admitted in NICU.

\section{Setting}

The present study was performed with Clinical Trial Code of IRCT20170726035328N2 in Shahid Motahari University Hospital during 2017-2018. This hospital offers advanced NICU services in the region.

\section{Sample}

A total of 96 mothers who had premature infants in NICU were selected as study sample. Sample size was calculated according to mean stress scores of subjects in the intervention and control groups as reported in the study by Di Blasio, Ionio, \& Confalonieri (2009). Sample size was measured with a confidence level of $99 \%$ and power of $90 \%$ as well as considering mean comparisons, consisting of 40 subjects per each group, and also taking into account $20 \%$ drop-out; thus 48 subjects were assigned to each group. Inclusion criteria were low level of education, no history of earlier premature births, and no history of acute stressful experience or drug abuse within the past 6 months, lack of any genetic diseases in the infant, and mother's presence in hospital. Exclusion criteria were neonate mortality and surgery, short length of stay in NICU (less than 10 days), and failure to keep expressive writing three times a week. To randomize the subjects, 96 envelopes were marked by either 1 or 2 , and were randomly distributed among the subjects. Those who received the envelope labeled as 1 were assigned to the control group, and the others were assigned to the intervention group. The subjects were informed about the procedure, and then an informed consent was obtained from all of them. Mothers in the intervention group were asked to find a private place and start expressing their deepest feelings, with no concerns about syntax and grammatical structure, toward their baby and its hospitalization in NICU. They were asked to start expressive writing from the third day of hospitalization and continue it three times a day for 15 min up to the tenth day of stay in NICU. The control group received routine care services. However, two subjects from the control group were excluded from the study due to non-compliance and neonatal death, and thus 46 subjects remained for analysis. Similarly, two subjects were excluded from the intervention group due to non-compliance and one case for neonatal death, as a result of which 45 subjects remained for analysis.

\section{Instrument}

\section{First, Demographic Questionnaire}

First, demographic questionnaire was distributed among the subjects, consisting the information about the mother 
including age, education level, number of children, economic status, history of infertility, history of child mortality, favored gender of baby, and satisfactoriness of pregnancy, along with the information about the infant including age, delivery type, Apgar score at 1-5 min, weight, and connection to mechanical ventilation. Then, the Edinburgh Postnatal Depression Scale (EPDS) was completed by the subjects in both groups on days 3 and 10, and 1-3 months after the admittance in NICU. Parental Stressor Scale for Neonatal Intensive Care Unit (PSS: NICU) was also completed by the participants in both groups on days 3 and 10. Finally, Cohen's Perceived Stress Scale-14 (PSS-14'COHEN) was completed by the subjects in both groups at 1-3 months after the admittance. All the questionnaires were filled out anonymously.

\section{Edinburgh}

Edinburgh Postnatal Depression Scale (EPDS) was developed by Cox in 1987 to measure level of depression in men and women (Cox, Holden, \& Sagovsky, 1987; Matthey and Agostini, 2017) reflecting the mother's feeling during the last week. The EPDS includes ten items in which each question is scored between 0 and 3, with a total score ranging between 0 and 30. Higher scores indicate depressive symptoms (Hawes et al., 2016). Items 1, 2, and 4 are reverse scored. Validity of the Persian edition of the EPDS was confirmed to be $>0.7$ according to the study by Montazeri et al. In their study, they compared it with SF36 with a correlative coefficient of $>0.4$ (Montazeri, Torkan, \& Omidvari, 2007).

\section{PSS: NICU}

PSS: NICU was designed by Miles-Funk-Carlson in 1993 to measure parental perception of stressors arising from physical and psychosocial environment of NICU. It includes 22 items scored on a 5-point Likert scale from 0 (no experience at all) to 5 (extremely stressful), with a total score ranging from 22 to 110. Higher scores indicate greater perceived stressor. PSS: NICU consists of three subscales measuring stress related to sights and sounds of the unit (six items), infant appearance and behaviors (eight items), parental role and their relationship with their baby and communication with the staff (eight items). Validity of the Persian edition of the questionnaire was confirmed in the study conducted by Kadivar et al. (2015). Internal consistency reliability was also confirmed. Cronbach's alpha coefficient was obtained as 0.87 (Kadivar \& Mozafarinia, 2013; Kadivar, et al., 2015).

\section{PSS-14'COHEN}

PSS-14'COHEN was developed by Cohen et al. to measure perceived stress during the last month (Cohen, Kamarck,
\& Mermelstein, 1983). It asks about feelings and thoughts related to stressful events, and controlling or coping with stressors. Content validity of this scale assessed by simple correlation coefficient was reported as 0.63 (Moghadam, Rashidzadeh, Shamsalizadeh, \& Fallahi, 2014). Reliability of the Persian edition of PSS-14'COHEN was confirmed in the studies conducted by Bastani et al. and Mohammadi et al., and Cronbach's alpha coefficient was reported as 0.74 (Bastani, Rahmatnejad, Jahdi, \& Haghani, 2008). Items are rated on a 5-point Likert scale (0 never; 1 almost never; 2 sometimes; 3 fairly often; 4 very often) with a total score ranging from 0 to 56 . Items $4-7,9,10$, and 13 are reverse scored. Higher score implies a higher level of perceived stress (Katsarou et al., 2012).

\section{Ethical Considerations}

The study was approved by the Ethics Committee of Urmia University of Medical Sciences (Ethics Code of IR.UMSU. REC.1396.103). Then, the research procedure was fully explained to the subjects, and they were informed that participation in the study was voluntary and non-participation did not deprive them from receiving regular medical care. An informed written consent was obtained from all the subjects, and the questionnaires were filled anonymously. They were reassured that their information would be kept confidential.

\section{Statistical Analysis and Results}

Mean age of mothers was equal to $30.43 \pm 6.85$ and $29.15 \pm 6.39$ years old, respectively, in the control and intervention groups, implying no significant difference $(p=0.36)$. Results of $\chi^{2}$ test showed no significant difference in terms of demographic information between the subjects, as represented in Table 1.

Table 2 summarizes demographic information of the infants. In case of multiple births, the lowest Apgar score and birth weight of the twins were considered. $\chi^{2}$ test showed no significant difference in terms of demographic information between the infants, i.e., the infants in two groups were homogenous.

Table 3 represents results obtained by the independent samples $T$ test. As shown in Table 3, Edinburgh postpartum depression scores on the third day of admittance in NICU were not significantly different in the control and intervention groups, but they were significant on the tenth day $(p=0.001)$, implying that expressive writing significantly influenced postpartum depression.

Results of the independent samples $T$-test presented in Table 4 reveal that mothers' stress score for sights and sounds of the unit was lower in the intervention group compared to the control group on the tenth day 
Table 1 Comparison of demographic information of mothers in the control and intervention groups

\begin{tabular}{|c|c|c|c|c|c|c|c|}
\hline \multirow[t]{2}{*}{ Variables } & \multicolumn{2}{|c|}{ Total $N=91$} & \multicolumn{2}{|c|}{ Control group $N=46$} & \multicolumn{2}{|c|}{ Intervention group $N=45$} & \multirow[t]{2}{*}{$p$ value* } \\
\hline & Frequency & $\begin{array}{l}\text { Relative fre- } \\
\text { quency } \%\end{array}$ & Frequency & $\begin{array}{l}\text { Relative fre- } \\
\text { quency } \%\end{array}$ & Frequency & $\begin{array}{l}\text { Relative fre- } \\
\text { quency } \%\end{array}$ & \\
\hline \multicolumn{8}{|l|}{ Mother's age } \\
\hline$<20$ & 4 & 4.4 & 1 & 2.2 & 3 & 6.7 & \multirow[t]{4}{*}{0.61} \\
\hline $20-29$ & 40 & 44 & 21 & 45.7 & 19 & 42.2 & \\
\hline $30-39$ & 41 & 45.1 & 20 & 43.5 & 21 & 46.7 & \\
\hline $40-59$ & 6 & 6.6 & 4 & 8.7 & 2 & 4.4 & \\
\hline \multicolumn{8}{|l|}{ Mother's educational level } \\
\hline Primary and secondary & 35 & 38.5 & 18 & 39.1 & 17 & 37.8 & \multirow[t]{3}{*}{0.05} \\
\hline High school & 23 & 25.3 & 16 & 34.8 & 7 & 15.6 & \\
\hline University & 33 & 36.3 & 12 & 26.1 & 21 & 46.7 & \\
\hline \multicolumn{8}{|l|}{ Mother's job } \\
\hline Working outside the home & 14 & 15.38 & 5 & 10.9 & 9 & 20 & \multirow[t]{2}{*}{0.22} \\
\hline Housewife & 77 & 84.62 & 41 & 89.1 & 36 & 80 & \\
\hline \multicolumn{8}{|l|}{ Having a previous child } \\
\hline Yes & 42 & 46.2 & 24 & 52.2 & 18 & 40 & \multirow[t]{2}{*}{0.24} \\
\hline No & 49 & 53.8 & 22 & 47.8 & 27 & 60 & \\
\hline \multicolumn{8}{|l|}{ Economic status $* *$} \\
\hline Low & 22 & 24.2 & 10 & 21.7 & 12 & 26.7 & \multirow[t]{3}{*}{0.33} \\
\hline Medium & 55 & 60.4 & 31 & 67.4 & 24 & 53.3 & \\
\hline High & 14 & 15.4 & 5 & 10.9 & 9 & 20 & \\
\hline \multicolumn{8}{|l|}{ History of infertility } \\
\hline Yes & 17 & 18.7 & 11 & 23.9 & 6 & 13.3 & \multirow[t]{2}{*}{0.19} \\
\hline No & 74 & 81.3 & 35 & 76.1 & 39 & 86.7 & \\
\hline \multicolumn{8}{|l|}{ History of child mortality } \\
\hline Yes & 7 & 7.7 & 4 & 8.7 & 3 & 6.7 & \multirow[t]{2}{*}{0.71} \\
\hline No & 84 & 92.3 & 42 & 91.3 & 42 & 93.3 & \\
\hline \multicolumn{8}{|l|}{ Favored gender of baby } \\
\hline Yes & 82 & 90.1 & 42 & 91.3 & 40 & 88.9 & \multirow[t]{2}{*}{0.70} \\
\hline No & 9 & 9.9 & 4 & 8.7 & 5 & 11.1 & \\
\hline \multicolumn{8}{|l|}{ Pregnancy being desired } \\
\hline Yes & 79 & 86.8 & 39 & 84.8 & 40 & 88.9 & \multirow[t]{2}{*}{0.56} \\
\hline No & 12 & 13.2 & 7 & 15.2 & 5 & 11.1 & \\
\hline
\end{tabular}

$* \chi^{2} ; * *$ low income less than expenses, medium income equals to expenses, high income more than expenses

$(32.04 \pm 8.78$ compared to $34.46 \pm 7.38)$, but the difference was not statistically significant $(p=0.15)$. Compared to the third day, there was a significant decrease in mean score of stress in both groups, but it was more evident in the intervention group on the tenth day. Mothers' stress score for infant appearance and behaviors was higher in the control group $(28.89 \pm 8.30)$ than that in the intervention group $(27.35 \pm 6.23)$, but the difference was not statistically significant $(p=0.32)$. Finally, mothers' stress scores for parental role showed slightly more decrease in the intervention group, implying that expressive writing effectively reduced stress during hospital stay.

Results of the independent samples $T$-test shown in Table 5 indicate higher stress scores in the control group before and after the intervention, but the difference was not statistically significant $(p=0.08)$.

Results of the independent samples $T$-test presented in Table 6 show that Edinburgh depression score was lower in the intervention group 1 and 3 months after admittance in NICU $(p=0.000)$. Cohen's perceived stress score was lower in the intervention group similar to the control group ( $p=0.000$ and $p=0.005)$, indicating that expressive writing significantly decreased postpartum depression and stress of mothers whose infants were in NICU for the medium term. 
Table 2 Comparison of demographic information of the infants in the control and intervention groups

\begin{tabular}{|c|c|c|c|c|c|c|c|}
\hline \multirow[t]{2}{*}{ Variables } & \multicolumn{2}{|c|}{ Total $N=91$} & \multicolumn{2}{|c|}{ Control group $N=46$} & \multicolumn{2}{|c|}{$\begin{array}{l}\text { Intervention group } \\
N=45\end{array}$} & \multirow[t]{2}{*}{$p$ value* } \\
\hline & Frequency & $\begin{array}{l}\text { Relative } \\
\text { fre- } \\
\text { quency \% }\end{array}$ & Frequency & $\begin{array}{l}\text { Relative } \\
\text { fre- } \\
\text { quency \% }\end{array}$ & Frequency & $\begin{array}{l}\text { Relative } \\
\text { fre- } \\
\text { quency \% }\end{array}$ & \\
\hline \multicolumn{8}{|c|}{ Apgar score at the first minute } \\
\hline $0-3$ & 9 & 9.9 & 4 & 8.7 & 5 & 11.1 & \multirow[t]{3}{*}{0.56} \\
\hline $4-7$ & 66 & 72.5 & 32 & 69.6 & 34 & 75.6 & \\
\hline $8-10$ & 16 & 17.6 & 10 & 21.7 & 6 & 13.3 & \\
\hline \multicolumn{8}{|c|}{ Apgar score at the fifth minute } \\
\hline $4-7$ & 24 & 26.4 & 8 & 17.4 & 16 & 35.6 & \multirow[t]{2}{*}{0.04} \\
\hline $8-10$ & 67 & 73.6 & 38 & 82.6 & 29 & 64.4 & \\
\hline \multicolumn{8}{|c|}{ Mechanical ventilation } \\
\hline Yes & 5 & 5.5 & 4 & 8.7 & 1 & 2.2 & \multirow[t]{2}{*}{0.17} \\
\hline No & 86 & 94.5 & 42 & 91.3 & 44 & 97.8 & \\
\hline \multicolumn{8}{|l|}{ Type of delivery } \\
\hline Vaginal delivery & 22 & 24.2 & 11 & 23.9 & 11 & 24.4 & \multirow[t]{2}{*}{0.95} \\
\hline Cesarean section & 69 & 75.8 & 35 & 76.1 & 34 & 75.6 & \\
\hline \multicolumn{8}{|c|}{ Gestational age to week } \\
\hline$<28$ & 6 & 6.6 & 5 & 10.9 & 1 & 2.2 & \multirow[t]{3}{*}{0.22} \\
\hline $28-32$ & 58 & 63.7 & 29 & 63 & 29 & 64.4 & \\
\hline $33-37$ & 27 & 29.7 & 12 & 26.1 & 15 & 33.3 & \\
\hline \multicolumn{8}{|c|}{ Weight of the neonate $(\mathrm{kg})$} \\
\hline$<1000$ & 8 & 8.8 & 6 & 13 & 2 & 4.4 & \multirow[t]{4}{*}{0.34} \\
\hline $1000-1499$ & 44 & 48.4 & 23 & 50 & 21 & 46.7 & \\
\hline $1500-2499$ & 34 & 37.4 & 14 & 30.4 & 20 & 44.4 & \\
\hline$<2500$ & 5 & 5.5 & 3 & 6.5 & 2 & 4.4 & \\
\hline
\end{tabular}

Table 3 Comparison of mean Edinburgh depression score in NICU in both control and intervention groups before and after the intervention

\begin{tabular}{|c|c|c|c|c|c|c|}
\hline \multirow[t]{3}{*}{ Variables } & \multicolumn{3}{|c|}{ The third day after the admission } & \multicolumn{3}{|c|}{ The tenth day after the admission } \\
\hline & Control group $N=46$ & $\begin{array}{l}\text { Intervention } \\
\text { group } N=45\end{array}$ & $p$ value* & Control group $N=46$ & $\begin{array}{l}\text { Intervention } \\
\text { group } N=45\end{array}$ & $p$ value* \\
\hline & $\mu \pm \mathrm{SD}$ & $\mu \pm \mathrm{SD}$ & & $\mu \pm \mathrm{SD}$ & $\mu \pm \mathrm{SD}$ & \\
\hline Edinburgh depression score & $9.65 \pm 5.28$ & $9.62 \pm 5.89$ & 0.98 & $9.23 \pm 5.41$ & $6.04 \pm 3.39$ & 0.001 \\
\hline
\end{tabular}

*Independent samples $T$ test

\section{Discussion}

The present study was carried out to investigate the effect of expressive writing on postpartum depression and stress of mothers who had premature infants. Results indicated that, on 10 days and 1-3 months after the admittance in NICU, stress level significantly dropped for mothers in the intervention group, while it increased for the mothers in the control group. On the other hand, mothers in the intervention group showed lower levels of stress than those in the control group, implying that expressive writing is effective in reducing the stressors, confirming our research hypothesis. However, both groups showed no significant differences in terms of demographic information and they were homogeneous. Sights and sounds of the unit were the most stressful factor for mothers in the control group on the third day of hospitalization. Expressive writing could significantly decrease stress level in this subscale. Environmental distractors such as light, noise, and monitoring equipment are main sources of stress for mothers whose infants are connected to a mechanical ventilator.

Our results regarding mean depression score on day 10 , and 1-3 months after admittance in NICU showed 
Table 4 Comparison of mean score of mothers' stress in NICU in three dimensions in both control and intervention groups before and after the intervention

\begin{tabular}{|c|c|c|c|c|c|c|}
\hline \multirow[t]{3}{*}{ Variables } & \multicolumn{3}{|c|}{ The third day after the admission } & \multicolumn{3}{|c|}{ The tenth day after the admission } \\
\hline & Control group $N=46$ & $\begin{array}{l}\text { Intervention group } \\
N=45\end{array}$ & $p$ value* & Control group $N=46$ & $\begin{array}{l}\text { Intervention group } \\
N=45\end{array}$ & $p$ value* \\
\hline & $\mu \pm \mathrm{SD}$ & $\mu \pm \mathrm{SD}$ & & $\mu \pm \mathrm{SD}$ & $\mu \pm \mathrm{SD}$ & \\
\hline $\begin{array}{l}\text { Infant appearance and } \\
\text { behaviors }\end{array}$ & $26.41 \pm 8.88$ & $26.75 \pm 6.94$ & 0.83 & $28.89 \pm 8.30$ & $27.35 \pm 6.23$ & 0.32 \\
\hline $\begin{array}{l}\text { Sights and sounds of } \\
\text { the unit }\end{array}$ & $33.17 \pm 6.61$ & $36.80 \pm 5.94$ & 0.007 & $32.04 \pm 8.78$ & $34.46 \pm 7.38$ & 0.15 \\
\hline Parental role & $19.89 \pm 6.54$ & $24.84 \pm 5.08$ & 0.000 & $21.50 \pm 6.39$ & $24.84 \pm 4.25$ & 0.004 \\
\hline Maternal stress score & $79.47 \pm 16.32$ & $88.40 \pm 13.34$ & 0.005 & $82.58 \pm 20.36$ & $86.55 \pm 13.89$ & 0.28 \\
\hline
\end{tabular}

*Independent samples $T$ Test

Table 5 Comparison of the differences between parents' stress score in both control and intervention groups before and after the intervention

\begin{tabular}{lll}
\hline Variable & $\begin{array}{l}\text { Control group } N=46 \\
\mu \pm \mathrm{SD}\end{array}$ & $\begin{array}{l}\text { Intervention group } N=45 \\
\mu \pm \mathrm{SD}\end{array}$ \\
\hline The differences between the parents' stress score before and after the intervention & $+3.10 \pm 14.35$ & $-1.84 \pm 12.84$ \\
\hline
\end{tabular}

*Independent samples $T$-test

Table 6 Comparison of mean Edinburgh Depression Scale and Cohen's Perceived Stress scores in the control and intervention groups after the intervention

\begin{tabular}{|c|c|c|c|c|c|c|}
\hline \multirow[t]{3}{*}{ Variables } & \multicolumn{3}{|c|}{1 months after admittance to NICU } & \multicolumn{3}{|c|}{3 months after admittance to NICU } \\
\hline & Control group $N=46$ & $\begin{array}{l}\text { Intervention } \\
\text { group } N=45\end{array}$ & $p$ value* & Control group $N=46$ & $\begin{array}{l}\text { Intervention } \\
\text { group } N=45\end{array}$ & $p$ value* \\
\hline & $\mu \pm \mathrm{SD}$ & $\mu \pm \mathrm{SD}$ & & $\mu \pm \mathrm{SD}$ & $\mu \pm \mathrm{SD}$ & \\
\hline Edinburgh depression score & $8.19 \pm 4.45$ & $2.95 \pm 2.41$ & 0.000 & $7.60 \pm 4.65$ & $2.44 \pm 2.01$ & 0.000 \\
\hline Cohen's perceived stress score & $23.54 \pm 9.39$ & $14.22 \pm 4.70$ & 0.000 & $23.04 \pm 7.18$ & $18.44 \pm 8.06$ & 0.000 \\
\hline
\end{tabular}

*Independent samples $T$ test

significant differences between the subjects in the control and intervention groups. So, mothers who kept a journal of expressive writing experienced lower levels of depression than those in the control group, also confirming the other research hypothesis that expressive writing significantly decreases postpartum depression and stress of mothers whose infants are in NICU.

Results of this study are in line with some other studies showing that medical team and nurses can benefit greatly from advantages of expressive writing in reducing parental stress and postpartum depression with cases of premature birth (Di Blasio et al., 2015; Horsch et al., 2016; Kadivar et al., 2015, 2017; Kolmakova, 2015; Niles, Haltom, Mulvenna, Lieberman, \& Stanton, 2014).

Expressive writing compared to emotionally neutral writings is a simple practice with long-lasting effects on physical and psychological health of individuals undergoing traumatic and distressing experiences (Pennebaker, 2018).

Results of a study showed that expressive writing significantly decreased stress scores in patients with major depressive disorder the day after the subjects started writing and continued it for 4 weeks. It has been shown that expressive writing has short- and long-term effects (Krpan et al., 2013). Results of some studies were inconsistent with our findings attributing to different study populations, low level of tension, and lack of previous traumatic experience (Jouybari et al., 2018; Merz, Fox, \& Malcarne, 2014; Reinhold et al., 2018; Sindoro, 2017).

Expressive writing is a convenient and costless intervention with no need for staff involvement and, according to Pennebaker, it improves physical as well as psychological health (Pennebaker \& Smyth, 2016). 
The present study was conducted to investigate the effect of expressive writing on postpartum depression and stress in mothers who had an infant in NICU on days 3 and 10 and also 1-3 months after the admittance. Because of time limitations, it was not possible to trace the effect of intervention on mental health of the mother and her relationship with the infant and its development after 3 months. Thus, it is suggested to consider a longer period starting from birthdate to a year after delivery in future studies. In addition, this study was conducted on mothers who had an infant hospitalized in NICU and did not include the fathers waiting outside the unit. In this regard, further studies are recommended to cover fathers as well in the parental stress analysis. Similar studies can also be carried out on high-risk pregnancies threatening mental health of parents and generating higher levels of stress.

\section{Conclusion}

Results of our study revealed that mothers whose infants were in NICU experienced a high level of postpartum depression and stress that may damage their relations with the infant. This highlights the need to develop support systems in order to provide care for both the mother and infant. Thus, according to findings of this study, expressive writing is proposed as a convenient and inexpensive means providing an opportunity for mothers to freely narrate their feelings in order to reduce levels of postpartum stress and depression.

Acknowledgements This paper was a part of a master's thesis on consultation in midwifery conducted at Urmia University of Medical Sciences (Urmia, Iran). The authors would like to thank the Vice Chancellery for the Research at Urmia University of Medical Sciences for their financial support. The authors also express their most sincere gratitude to all the mothers and the staff of NICU at Shahid Motahari University Hospital, Urmia, Iran, who participated and contributed in the present study.

\section{Compliance with Ethical Standards}

Conflicts of interest The authors Soheila Rabiepoor, Naemeh Vatankhah-Alamdary, and Hamid Reza Khalkhali declare that they have no conflict of interest.

Human and Animal Rights All procedures were in accordance with the ethical standards of the institutional research committees and with the 1964 Helsinki declaration and its later amendments or comparable ethical standards.

Informed Consent Informed consent was obtained from all individual participants included in the study.

\section{References}

Althabe, F. (2012). Born too soon: The global action report on preterm birth. Geneva: World Health Organization.
Bastani, F., Rahmatnejad, L., Jahdi, F., \& Haghani, H. (2008). Breastfeeding self efficacy and perceived stress in primiparous mothers. Iran Journal of Nursing, 21, 9-24.

Chertok, I. R. A., McCrone, S., Parker, D., Leslie, N., \& Catlin, A. (2014). Review of interventions to reduce stress among mothers of infants in the NICU. Advances in Neonatal Care, 14, 30-37.

Cohen, S., Kamarck, T., \& Mermelstein, R. (1983). A global measure of perceived stress. Journal of Health and Social Behavior, 24, 385-396.

Cox, J. L., Holden, J. M., \& Sagovsky, R. (1987). Detection of postnatal depression. Development of the 10-item Edinburgh Postnatal Depression Scale. The British Journal of Psychiatry, 150, 782-786.

Di Blasio, P., Camisasca, E., Caravita, S. C. S., Ionio, C., Milani, L., \& Valtolina, G. G. (2015). The effects of expressive writing on postpartum depression and posttraumatic stress symptoms. Psychological Reports, 117, 856-882.

Di Blasio, P., Ionio, C., \& Confalonieri, E. (2009). Symptoms of postpartum PTSD and expressive writing: A prospective study. Journal of Prenatal \& Perinatal Psychology \& Health, 24, 49.

Dolatian, M., Mirabzadeh, A., Forouzan, A. S., Sajjadi, H., Majd, H. A., \& Moafi, F. (2013). Preterm delivery and psycho-social determinants of health based on World Health Organization model in Iran: A narrative review. Global Journal of Health Science, 5, 52.

Drake, J. E., \& Winner, E. (2012). Confronting sadness through artmaking: Distraction is more beneficial than venting. Psychology of Aesthetics, Creativity, and the Arts, 6, 255.

Hasanpour, S., Ouladsahebmadarek, E., Hosseini, M. B., Mirghafourvand, M., Heidarabadi, S., \& Jafarabadi, M. A. (2018). Mother-infant attachment at the age of 1 year in recipients of developmental care after preterm birth. Development, 21, 22.

Hawes, K., McGowan, E., O’donnell, M., Tucker, R., \& Vohr, B. (2016). Social emotional factors increase risk of postpartum depression in mothers of preterm infants. The Journal of Pediatrics, $179,61-67$.

Horsch, A., Tolsa, J.-F., Gilbert, L., Du Chêne, L. J., Müller-Nix, C., \& Graz, M. B. (2016). Improving maternal mental health following preterm birth using an expressive writing intervention: A randomized controlled trial. Child Psychiatry and Human Development, 47, 780-791.

Jouybari, L., Abbariki, E., Jebeli, M., Mehravar, F., Asadi, L., Akbari, N., ..., Moradi, Z. (2018). Comparison of the effect of narrative writing and art therapy on maternal stress in neonatal intensive care settings. The Journal of Maternal-Fetal \& Neonatal Medicine. https://doi.org/10.1080/14767058.2018.1499719.

Kadivar, M., \& Mozafarinia, S. M. (2013). Supporting fathers in a NICU: Effects of the HUG Your Baby program on fathers' understanding of preterm infant behavior. The Journal of Perinatal Education, 22, 113.

Kadivar, M., Seyedfatemi, N., Akbari, N., \& Haghani, H. (2015). The effect of narrative writing on maternal stress in neonatal intensive care settings. The Journal of Maternal-Fetal \& Neonatal Medicine, 28, 938-943.

Kadivar, M., Seyedfatemi, N., Akbari, N., Haghani, H., \& Fayaz, M. (2017). Evaluation of the effect of narrative writing on the stress sources of the parents of preterm neonates admitted to the NICU. The Journal of Maternal-Fetal \& Neonatal Medicine, 30, 1616-1620.

Katsarou, A., Panagiotakos, D., Zafeiropoulou, A., Vryonis, M., Skoularigis, I., Tryposkiadis, F., \& Papageorgiou, C. (2012). Validation of a Greek version of PSS-14; a global measure of perceived stress. Central European Journal of Public Health, 20, 104-109.

Kolmakova, D. (2015). Support for the parents whose child is in Neonatal Intensive Care Unit (NICU).

Krpan, K. M., Kross, E., Berman, M. G., Deldin, P. J., Askren, M. K., \& Jonides, J. (2013). An everyday activity as a treatment for 
depression: The benefits of expressive writing for people diagnosed with major depressive disorder. Journal of Affective Disorders, 150, 1148-1151.

Lasiuk, G. C., Comeau, T., \& Newburn-Cook, C. (2013). Unexpected: An interpretive description of parental traumas' associated with preterm birth. BMC Pregnancy and Childbirth, 13, S13.

Lefkowitz, D. S., Baxt, C., \& Evans, J. R. (2010). Prevalence and correlates of posttraumatic stress and postpartum depression in parents of infants in the Neonatal Intensive Care Unit (NICU). Journal of Clinical Psychology in Medical Settings, 17, 230-237.

Matthey, S., \& Agostini, F. (2017). Using the Edinburgh postnatal depression scale for women and men-Some cautionary thoughts. Archives of Women's Mental Health, 20, 345-354.

Merz, E. L., Fox, R. S., \& Malcarne, V. L. (2014). Expressive writing interventions in cancer patients: A systematic review. Health Psychology Review, 8, 339-361.

Milbury, K., Lopez, G., Spelman, A., Wood, C., Matin, S. F., Tannir, N. M., \& Cohen, L. (2017). Examination of moderators of expressive writing in patients with renal cell carcinoma: The role of depression and social support. Psycho-Oncology, 26, 1361-1368.

Misund, A. R., Nerdrum, P., \& Diseth, T. H. (2014). Mental health in women experiencing preterm birth. BMC Pregnancy and Childbirth, 14, 263.

Mizutani, N. (2016). Parents' experiences of music therapy in the Neonatal Intensive Care Unit (NICU).

Moghadam, M., Rashidzadeh, S., Shamsalizadeh, N., \& Fallahi, B. (2014). The impact of stress management training on the copping style and perceived stress in medical students. Scientific Journal of Kurdistan University of Medical Sciences, 19, 52-60.

Montazeri, A., Torkan, B., \& Omidvari, S. (2007). The Edinburgh Postnatal Depression Scale (EPDS): Translation and validation study of the Iranian version. BMC Psychiatry, 7, 11.

Morgan, M. C., Nambuya, H., Waiswa, P., Tann, C., Elbourne, D., Seeley, J., ..., Lawn, J. E. (2018). Kangaroo mother care for clinically unstable neonates weighing $\leq 2000 \mathrm{~g}$ : Is it feasible at a hospital in Uganda? Journal of global health, 8, 010701.

Murray, L., Halligan, S., \& Cooper, P. (2010). Effects of postnatal depression on mother-infant interactions and child development.
The Wiley-Blackwell Handbook of Infant Development, 2, 192-220.

Niles, A. N., Haltom, K. E., Mulvenna, C. M., Lieberman, M. D., \& Stanton, A. L. (2014). Randomized controlled trial of expressive writing for psychological and physical health: The moderating role of emotional expressivity. Anxiety Stress and Coping, 27, $1-17$.

Pennebaker, J. W. (2018). Expressive writing in psychological science. Perspectives on Psychological Science, 13, 226-229.

Pennebaker, J. W., \& Smyth, J. M. (2016). Opening up by writing it down: How expressive writing improves health and eases emotional pain. New York: Guilford Publications.

Perry, J. A., \& Ward-Smith, P. (2018). Expressive writing as an intervention to decrease distress in pediatric critical care nurses. Clinical Nursing Studies, 6, 96.

Reinhold, M., Bürkner, P. C., \& Holling, H. (2018). Effects of expressive writing on depressive symptoms-A meta-analysis. Clinical Psychology: Science and Practice, 25, e12224.

Rude, S. S., \& Haner, M. L. (2018). Individual differences matter: Commentary on "Effects of expressive writing on depressive symptoms-A meta-analysis". Clinical Psychology: Science and Practice, 25, e12230.

Russell, G., Sawyer, A., Rabe, H., Abbott, J., Gyte, G., Duley, L., \& Ayers, S. (2014). Parents' views on care of their very premature babies in neonatal intensive care units: A qualitative study. $B M C$ Pediatrics, 14, 230.

Sadock, B. J., Sadock, V. A., \& Ruiz, P. (2014). Kaplan \& Sadock's synopsis of psychiatry: Behavioral sciences/clinical psychiatry (11th ed.). Philadelphia: Wolters Kluwer.

Sindoro, L. F. (2017). The effectiveness of expressive writing as a reductor of psychological distress. In UI proceedings on social science and humanities (Vol. 1).

Publisher's Note Springer Nature remains neutral with regard to jurisdictional claims in published maps and institutional affiliations. 